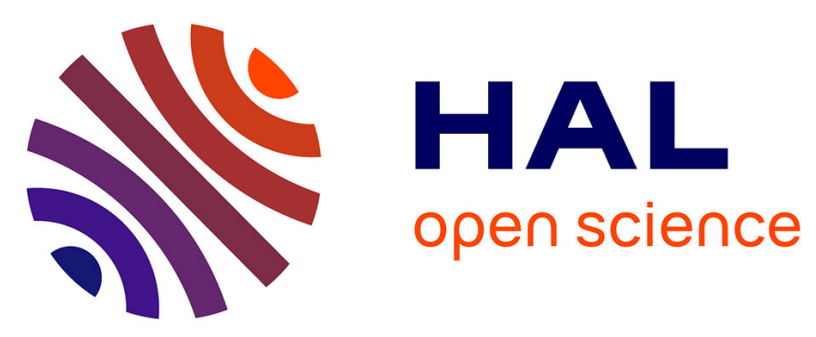

\title{
H-NS mediated repression of CRISPR-based immunity in Escherichia coli K12 can be relieved by the transcription activator LeuO
}

Edze Rients Westra, Ümit Pul, Nadja Heidrich, Matthijs Miklas Jore, Magnus Lundgren, Thomas Stratmann, Reinhild Wurm, Amanda Raine, Melina

Mescher, Luc Van Heereveld, et al.

\section{To cite this version:}

Edze Rients Westra, Ümit Pul, Nadja Heidrich, Matthijs Miklas Jore, Magnus Lundgren, et al.. H-NS mediated repression of CRISPR-based immunity in Escherichia coli K12 can be relieved by the transcription activator LeuO. Molecular Microbiology, 2010, 77 (6), pp.1380. 10.1111/j.13652958.2010.07315.x . hal-00560024

\section{HAL Id: hal-00560024 https://hal.science/hal-00560024}

Submitted on 27 Jan 2011

HAL is a multi-disciplinary open access archive for the deposit and dissemination of scientific research documents, whether they are published or not. The documents may come from teaching and research institutions in France or abroad, or from public or private research centers.
L'archive ouverte pluridisciplinaire $\mathbf{H A L}$, est destinée au dépôt et à la diffusion de documents scientifiques de niveau recherche, publiés ou non, émanant des établissements d'enseignement et de recherche français ou étrangers, des laboratoires publics ou privés. 


\section{molecular microbiology}

\section{H-NS mediated repression of CRISPR-based immunity in Escherichia coli K12 can be relieved by the transcription activator LeuO}

\begin{tabular}{|c|c|}
\hline Journal: & Molecular Microbiology \\
\hline Manuscript ID: & MMI-2010-10275.R1 \\
\hline Manuscript Type: & Research Article \\
\hline $\begin{array}{r}\text { Date Submitted by the } \\
\text { Author: }\end{array}$ & 07-Jul-2010 \\
\hline Complete List of Authors: & $\begin{array}{l}\text { Westra, Edze; Wageningen University, Microbiology } \\
\text { Pul, Ümit; Heinrich-Heine-Universität Düsseldorf, Düsseldorf, } \\
\text { Germany, Molecular Biology of Prokaryotes } \\
\text { Heidrich, Nadja; Uppsala University, Institute of Cell and Molecular } \\
\text { Biology } \\
\text { Jore, Matthijs; Wageningen University, Laboratory of Microbiology } \\
\text { Lundgren, Magnus; Uppsala University, Institute of Cell and } \\
\text { Molecular Biology } \\
\text { Stratmann, Thomas; University of Cologne, Institute for Genetics } \\
\text { Wurm, Reinhild; Heinrich-Heine-Universität Düsseldorf, Molecular } \\
\text { Biology of Prokaryotes } \\
\text { Raine, Amanda; Uppdala University, Department of Cell and } \\
\text { Molecular Biology } \\
\text { Mescher, Melina; Heinrich-Heine-Universität Düsseldorf, Molecular } \\
\text { Biology of Prokaryotes } \\
\text { Heereveld, Luc; Wageningen University, Laboratory of Microbiology } \\
\text { Mastop, Marieke; Wageningen University, Laboratory of } \\
\text { Microbiology } \\
\text { Wagner, E. Gerhart H.; Uppsala university, Department of Cell and } \\
\text { Molecular Biology } \\
\text { Schnetz, Karin; University of Cologne, Institute for Genetics } \\
\text { Van der Oost, John; Wageningen University, Laboratory of } \\
\text { Microbiology } \\
\text { Wagner, Rolf; Heinrich-Heine-Universität Düsseldorf, Molecular } \\
\text { Biology of Prokaryotes } \\
\text { Brouns, Stan; Wageningen University, Laboratory of Microbiology }\end{array}$ \\
\hline Key Words: & CRISPR, bacteria, regulation, H-NS, LeuO \\
\hline
\end{tabular}




\section{SCHOLARONE ${ }^{m}$ Manuscripts}

Page 1 of 42 
$24{ }^{5}$ these authors contributed equally

$25 *$ Correspondence: stan.brouns@wur.nl and r.wagner@rz.uni-duesseldorf.de

H-NS mediated repression of CRISPR-based immunity in Escherichia coli K12 can be relieved by the transcription activator LeuO Running title: LeuO activates CRISPR-based immunity Keywords: CRISPR, bacteria, regulation, H-NS, LeuO, phage defense

Edze R. Westra ${ }^{1,5}$, Ümit Pul ${ }^{2,5}$, Nadja Heidrich ${ }^{3}$, Matthijs M. Jore ${ }^{1}$, Magnus Lundgren $^{3}$, Thomas Stratmann ${ }^{4}$, Reinhild Wurm ${ }^{2}$, Amanda Raine ${ }^{3}$, Melina Mescher ${ }^{2}$, Luc van Heereveld ${ }^{1}$, Marieke Mastop ${ }^{1}$, E. Gerhart H. Wagner ${ }^{3}$, Karin Schnetz ${ }^{4}$, John van der Oost ${ }^{1}$, Rolf Wagner ${ }^{2 *}$, Stan J. J. Brouns ${ }^{1 *}$

${ }^{1}$ Laboratory of Microbiology, Department of Agrotechnology and Food Sciences, Wageningen University, Dreijenplein 10, 6703 HB Wageningen, The Netherlands ${ }^{2}$ Institut für Physikalische Biologie, Heinrich-Heine-Universität Düsseldorf, Universitätsstr. 1, D-40225 Düsseldorf, Germany

${ }^{3}$ Department of Cell and Molecular Biology, Uppsala University, Husargatan 3, SE75124 Uppsala, Sweden

${ }^{4}$ Institute for Genetics, University of Cologne, Zülpicher Strasse 47, 50674 Cologne, Germany

\section{(3)}




\section{Summary}

2 The recently discovered prokaryotic CRISPR/Cas defense system provides immunity

3 against viral infections and plasmid conjugation. It has been demonstrated that in

4 Escherichia coli transcription of the Cascade genes (casABCDE) and to some extent

5 the CRISPR array, is repressed by heat-stable nucleoid-structuring (H-NS) protein, a

6 global transcriptional repressor. Here we elaborate on the control of the E. coli

7 CRISPR/Cas system, and study the effect on CRISPR-based anti-viral immunity.

8 Transformation of wildtype E. coli K12 with CRISPR spacers that are complementary

9 to phage Lambda, does not lead to detectable protection against Lambda infection.

10 However, when an H-NS mutant of E. coli K12 is transformed with the same anti-

11 Lambda CRISPR, this does result in reduced sensitivity to phage infection. In addition,

12 it is demonstrated that LeuO, a LysR-type transcription factor, binds to two sites

13 flanking the casA promoter and the H-NS nucleation site, resulting in derepression of 14 casABCDE12 transcription. Over-expression of LeuO in E. coli K12 containing an 15 anti-Lambda CRISPR leads to an enhanced protection against phage infection. This 16 study demonstrates that in E. coli $\mathrm{H}-\mathrm{NS}$ and LeuO are antagonistic regulators of 17 CRISPR-based immunity. 


\section{Introduction}

2 Invasions by viruses and conjugative plasmids pose a threat to microbial cells. To

3 neutralize selfish DNA elements, bacteria and archaea have developed several defense

4 strategies, such as receptor masking, restriction/modification and abortive infection

5 (Hyman and Abedon, 2010; Labrie et al., 2010). Recently it was discovered that

6 Clustered Regularly Interspaced Short Palindromic Repeats (CRISPR) (Ishino et al.,

7 1987) and $\underline{\text { CRISPR }}$ associated (cas) genes (Jansen et al., 2002) form a sophisticated

8 immune system that uses small RNAs to target mobile genetic elements, reviewed by

9 (Horvath and Barrangou, 2010; Karginov and Hannon, 2010; Marraffini and

10 Sontheimer, 2010; van der Oost et al., 2009). CRISPRs consist of repeating sequences

11 of approximately 30 nucleotides that are separated by unique sequences of similar size,

12 called spacers (Mojica et al., 2000). The spacer sequences are commonly derived

13 from phages and plasmids (Bolotin et al., 2005; Mojica et al., 2005; Pourcel et al.,

14 2005), and new spacers can be added to the existing CRISPR array, expanding the

15 invader repertoire (Barrangou et al., 2007), in a process known as CRISPR adaptation.

16 The presence of a spacer matching a viral or plasmid sequence confers resistance to

17 invasion by these elements (Barrangou et al., 2007; Brouns et al., 2008; Marraffini

18 and Sontheimer, 2008). The biochemical pathways underlying CRISPR defense are

19 partially known and involve transcription of the array into a long precursor CRISPR

20 RNA. This precursor is cleaved in the repeat sequences by a Cas endonuclease (CasE

21 in E. coli (Brouns et al., 2008), Cas6 in Pyrococcus furiosus (Carte et al., 2008)),

22 releasing small crRNAs that serve to guide the defense.

23 The cas genes encode the protein machinery that carries out the various steps

24 of CRISPR defense. Approximately 45 families of cas genes have been identified 
1 (Haft et al., 2005) that are classified in eight typical combinations or subtypes named

2 after a representative organism, e.g. type E after E. coli (Haft et al., 2005).

The type E CRISPR/Cas immune system in E. coli $\mathrm{K} 12$ is composed of 8 cas genes (cas1, cas2, cas3 and casABCDE) and a downstream CRISPR locus with type 2 repeats (Kunin et al., 2007) containing 12 spacer-repeat units (CRISPR I) (Fig. 1A). An additional 6 spacer-containing CRISPR (CRISPR II) and a 2 spacer CRISPR al., 2007) containing 1 spacer repeat unit (CRISPR IV) are located elsewhere on the genome (Diez-Villasenor et al., 2010). In addition to a CRISPR containing an antiinvader sequence, only Cas3 and Cas $\mathrm{ABCDE}$, forming the protein complex Cascade

11 (CRISPR-associated complex for antiviral defense), are required for CRISPR interference (Brouns et al., 2008). A recent study has demonstrated that in E. coli K12 transcription from the $\operatorname{cas} A$ and CRISPR I promoters is repressed by heat-stable nucleoid-structuring protein (H-NS) (Pul et al., 2010), a global repressor of transcription in many Gram-negative bacteria. A microarray study indicates that transcription of casABC and cas 2 is elevated in an E. coli $\mathrm{K} 12 \Delta h n s$ strain compared to wt E. coli K12 (Hommais et al., 2001). In addition, H-NS was shown to possess high binding affinity for the intergenic region between cas3 and casA (Oshima et al., 2006;

19 Pul et al., 2010). H-NS has a preference for binding AT-rich DNA sequences 20 (Navarre et al., 2006). After initial binding of H-NS to high affinity nucleation sites 21 (Bouffartigues et al., 2007; Lang et al., 2007) repression of transcription is mediated by cooperative spreading along the DNA (defined as DNA stiffening (Liu et al., 2010))

23 and by creating looped structures through formation of DNA-protein-DNA bridges 24 (Dame et al., 2005). Moreover, H-NS acts as a DNA structuring protein (Liu et al., 25 2010; Stoebel et al., 2008). 
Overcoming H-NS mediated repression of cas gene transcription may be a key

2 requirement for CRISPR/Cas functionality. Generally, H-NS repression can be

3 relieved by a number of proteins, such as SlyA, VirB and others (Stoebel et al., 2008).

4 One of these proteins is the regulator LeuO (Chen and $\mathrm{Wu}, 2005$; De la Cruz et al.,

5 2007), which belongs to the LysR family of transcription factors (Stoebel et al., 2008)

6 and is found in all proteobacteria, except the $\delta$ subdivision (Maddocks and Oyston,

7 2008). The leuO gene maps next to the leuABCD operon (Chen et al., 2005; Chen and

8 Wu, 2005; Hertzberg et al., 1980), whose gene products are required for leucine

9 synthesis (Vartak et al., 1991). Recent data indicate that LeuO is involved in

10 regulating transcription of many genes, often as an H-NS antagonist (Shimada et al.,

11 2009; Stoebel et al., 2008). However, since under laboratory growth conditions the

12 genomic leuO gene itself is repressed by H-NS (Klauck et al., 1997; Majumder et al.,

13 2001) all LeuO regulation studies make use of plasmid encoded leuO under control of

14 constitutive or inducible promoters. In the host environment leuO is likely to be

15 induced under certain conditions as for example virulence of Salmonella enterica 16 leuO mutants is attenuated (Lawley et al., 2006).

A genomic screen for LeuO-binding DNA fragments in E. coli $\mathrm{K} 12$ revealed

1812 gene clusters, including the casA-cas 2 operon $(y g c L, y g c K, y g c J, y g c I, y g c H, y g b T$,

$19 y g b F)$ (Shimada et al., 2009). When LeuO was over-expressed, increased expression

20 of casA and cas2 was observed in E. coli (Shimada et al., 2009), and of casA

21 (STY3070) in Salmonella enterica serovar Typhi (Hernandez-Lucas et al., 2008). We

22 therefore investigated whether LeuO can mediate H-NS derepression of cas gene and

23 CRISPR transcription. In this study we demonstrate that LeuO counteracts H-NS-

24 dependent repression of the casA promoter by reorganizing the DNA protein contacts

25 within the transcription initiation region. The resulting change results in increased 
1 transcription of the Cascade genes, the limiting factor for CRISPR-based defense 2 against phage infection in E. coli $\mathrm{K} 12$.

\section{$4 \quad$ Results}

\section{$5 \quad$ LeuO activates cas gene expression}

6 To study the effect of LeuO on cas gene expression, transcript levels of the E. coli

7 K12 cas genes in mid-exponential growth phase were examined using a DNA microarray approach. RNA samples isolated from a wt E. coli $\mathrm{K} 12$ strain containing a leuO encoding plasmid were compared to RNA isolated from a strain containing the empty vector. In addition, RNA isolated from a $\Delta l e u O$ mutant carrying the empty

11 vector was analyzed. Comparison of cas gene transcription levels between the LeuO-

12 expressing strain and the control strain revealed a significant upregulation of 13 transcription of casABCDE and cas1 and cas 2 transcription, showing a gradual 14 decrease from casA (65-fold) to cas2 (5-fold) (Table 1). No change in the 15 transcription level of cas3 was detected. These results are consistent with a 16 polycistronic transcription of the $\operatorname{cas} A B C D E$ and possibly the cas 1 , cas 2 genes, with 17 polar effects for the transcription of the more downstream genes. However, we did not 18 observe significant differences in cas gene transcription in the $\Delta l e u O$ mutant 19 compared to the wildtype strain (Table 1), indicating that leuO is not expressed under 20 the growth conditions used here.

To verify the observed increase in cas gene expression levels, quantitative PCR (qPCR) was performed on total RNA isolated from 3 strains during midexponential phase: $w t$ E. coli, a $\Delta h n s$ strain and a $w t$ strain expressing leuO from a

24 plasmid. This analysis showed that casABCDE displayed increased transcription in 25 both hns knockout and leuO expressing strains (Fig. 1B). While the increase in 
1 cas $A B C D E$ transcripts was modest in hns knockout strains, on average 5-fold, the

2 effect of introducing leuO was more dramatic, with an average increase of 236-fold

3 after induction of $l e u O$ expression. An increase in casABCDE transcripts was also

4 observed when leuO expression was not induced, due to leakage from the PT5/lac

5 promoter. The cas 1 and cas 2 genes also displayed increased transcript abundance in

6 leuO expressing strains, although at lower levels than $\operatorname{cas} A B C D E$. Consistent with the

7 microarray data, a trend of transcript fold change was observed, with polar effects

8 downstream of $\operatorname{cas} A$, again suggesting a polycistronic mRNA of the casABCDE12

9 operon. Compared to the effect on the other cas genes, only a small increase of cas3

10 transcription was observed in $l e u O$ expressing strains.

11 To further evaluate the effects of $\mathrm{H}-\mathrm{NS}$ and LeuO on transcription from the 12 casA promoter (known as Pcas (Pul et al., 2010)), RNA samples from wt strains 13 expressing leuO from a plasmid and strains lacking hns were compared by primer 14 extension analysis. No cas transcripts were detected in wt cells containing an empty 15 expression vector. Transcripts directed from Pcas were only detected in cells 16 expressing leuO from a plasmid or in hns knockout strains (Fig. S1), indicating that 17 transcription of the casABCDE12 operon is tightly controlled by H-NS and LeuO.

\section{LeuO causes increased crRNA abundance}

20 The CRISPR I locus is transcribed in E. coli K12 and the transcript is cleaved by the

21 CasE subunit of Cascade into small crRNAs that subsequently remain bound by 22 Cascade (Brouns et al., 2008; Pul et al., 2010). In K12 small crRNAs were virtually 23 undetectable by Northern blot analysis (Brouns et al., 2008) and (Fig. 2A). To 24 investigate whether this was due to too low transcription levels of casABCDE, the wt 25 strain was transformed with a plasmid encoding the Cascade protein components 
1 under control of an arabinose-inducible promoter. In the wt strain expressing casABCDE from a plasmid, crRNAs with a length of about 60 nt could be detected. The requirement for plasmid-encoded synthesis of Cascade for detection of small crRNAs indicates that the level of Cascade in wt E. coli is insufficient for generating and stabilizing mature crRNAs. Furthermore we analyzed the levels of crRNAs in an $h n s$ knockout strain and in the $w t$ strain expressing leuO constitutively from a plasmid. Both deletion of hns and over-expression of leuO caused significant crRNA accumulation, due to enhanced expression of Cascade in these two strains (Fig. 2B and 2C). The CasA knockout strain (JW2730) serves as a control and marker for the mature crRNA. It was previously shown that a CasA knockout strain generates elevated levels of mature crRNA (Brouns et al., 2008), due to read-through of the downstream cas genes from the kanamycin resistance marker containing recombination cassette by which the casA gene is replaced (Pougach et al., in press).

\section{Binding of LeuO and H-NS to the DNA sequence upstream of casA}

The casA-cas3 intergenic region (here denoted IGLB) contains Pcas, for which H-NS has strong binding affinity as well as the divergently oriented anti-cas3 (known as anti-Pcas) promoter, that is located 80 bp upstream of Pcas and gives rise to an antisense transcript of unknown function (Fig. 1A and Fig. 3C) (Pul et al., 2010).

Both LeuO and H-NS bind the IGLB fragment, as determined by Electrophoretic Mobility Shift Assay (EMSA) (Fig. 3A, lanes 2-4 and 5-7). Pre-bound LeuO impedes cooperative binding of H-NS to the IGLB fragment (Fig. 3A, lanes 911). In line with this, pre-bound H-NS is partly released from the DNA when LeuO is added to the complex (Fig. 3A lanes 12-15). In order to map the binding region of LeuO within the IGLB fragment DNase I footprint analysis was performed. Upon 
1 limited DNase I hydrolysis of the IGLB DNA fragment, H-NS causes an extended

2 footprint (Fig. 3B), as shown before (Pul et al., 2010). In addition, LeuO protects two

3 sites (site 1 and site 2) within the IGLB fragment that flank the high affinity H-NS

4 nucleation site (Fig. 3B and 3C). LeuO site 1 is located 20 bp downstream of Pcas and

5 LeuO site 2 spans the divergent anti-Pcas (Fig. 3B and 3C). Interestingly, in the

6 presence of LeuO the extended protection by H-NS is no longer visible (Fig. 3B,

7 compare lanes 2 and 4), indicating that due to LeuO binding the DNA region

8 containing the H-NS high-affinity binding site is no longer protected from DNase I

9 cleavage, in agreement with decreased cooperative binding (Fig. 3A).

10 In order to analyze the effect of LeuO on RNA polymerase (RNAP) binding to

11 the promoter sites, DNase I footprints were performed in the presence of RNAP and

12 LeuO. Moreover, the effect on transcription initiation and RNAP open complex

13 formation was analyzed by $\mathrm{KMnO}_{4}$ footprints of stable initiation complexes. RNAP

14 binds to the two promoters (Pcas and anti-Pcas) (Fig. 4A, lanes 3 and 3', indicated I

15 (Pcas) and II (anti-Pcas)) (Pul et al., 2010). Addition of the DNA binding proteins

$16 \mathrm{LeuO}$ or $\mathrm{H}-\mathrm{NS}$ alone does not cause changes in the $\mathrm{KMnO}_{4}$ reactivity (Fig. 4A, lanes

$172^{\prime}, 4^{\prime}$ and 5'). Binding of LeuO abolishes the spreading of H-NS along the DNA,

18 resulting in a lack of protection by H-NS in the region between positions -160 to -240

19 (Fig. 4A, compare lanes 2 and 5), as observed before (Fig. 3B). When RNAP binding

20 was studied in the presence of both transcription factors it turned out that the order of

21 addition to the DNA is crucial for the resulting footprint. RNAP binding was only

22 affected when H-NS and/or LeuO were added to the DNA prior to RNAP. While prior

23 binding of H-NS to the IGLB DNA fragment completely abolished RNAP-promoter

24 interaction and open complex formation (Fig. 4A and 4B, compare lanes $3^{\prime}$ and 6'),

25 prior binding of LeuO had a repressive effect only on RNAP binding at anti-Pcas (Fig. 
$14 \mathrm{~A}$ and $4 \mathrm{~B}$, compare lanes $3^{\prime}$ and 7'; Fig. 4E, lane 5'). This can also be seen on the 2 retardation gels (Fig. 4C and 4D), where the DNA/RNAP complex II is lost in the 3 presence of LeuO (Fig. 4C, lane 7). This complex remains stable when H-NS is added 4 last (Fig. 4C, lane 9), in contrast to a sample with only H-NS or where H-NS is added

5 before LeuO (Fig. 4C, lanes 6 or 8, respectively). Moreover, the change in nucleotide 6 reactivities indicates that LeuO binding alters the architecture of the transcription 7 initiation complex at the Pcas promoter (compare Fig. 4B, lanes 7' with Fig. 4A, line $8 \quad 3^{\prime}$ and Fig. 4E, lane 3' with lane 5'). Altogether these data indicate that LeuO plays an 9 important role in the regulation of casABCDE12 gene expression by antagonizing $\mathrm{H}$ 10 NS-dependent repression of Pcas.

\section{H-NS and LeuO regulate CRISPR-based immunity against phage infection}

13 The effect of H-NS on CRISPR-based defense against phage infection was analyzed 14 in $w t$ and $\Delta h n s$ E. coli strains, grown in Luria Bertani broth. Since none of the spacers 15 of E. coli K12 target known bacteriophages, an artificial seven spacer CRISPR (J3) with the native promoter was designed containing one spacer that targets the template strand of the gene encoding the phage Lambda tail protein $(\mathrm{J})$. A non-targeting $(\mathrm{N})$ CRISPR (Brouns et al., 2008) served as a negative control. Introducing the J3

19 CRISPR reduced the sensitivity to virulent phage Lambda $\left(\lambda_{\text {vir }}\right)$ infection 4 -fold in the $\Delta h n s$ but not in the $w t$ strain (Fig. 5A). Complementation of the $\Delta h n s$ strain

21 reversed the reduction in phage sensitivity, demonstrating that CRISPR-based defense 22 is negatively regulated by H-NS (Fig. 5A). When cells were grown in richer media 23 (2YT) until stationary growth phase, higher resistance levels were observed, up to a 24 10-fold reduced sensitivity compared to a non-targeting strain (data not shown). 
1 Moreover, plaques were much smaller in the hns knockout strains equipped with the

2 J3 CRISPR when using 2YT.

Further evidence that H-NS controls CRISPR-based immunity was obtained

$4 \quad$ using genetically engineered strains (Table S4) in which the genomic CRISPR I locus

5 was replaced by the $\mathrm{J} 3$ or a non-targeting CRISPR. E. coli K12 $\triangle$ CRISPRI::CRISPRJ3

6 (E. coli J3) was fully sensitive to infection by phage Lambda, despite the presence of

7 a genomic J3 spacer (Fig. S2). However, when the dominant negative $h n s^{\mathrm{G} 113 \mathrm{D}}$ mutant

8 was expressed from a plasmid, the sensitivity of E. coli $\mathrm{J} 3$ to phage $\lambda_{\text {vir }}$ infection was

9 reduced 3.6 fold (Fig. S2). This mutant still forms heterodimers with $w t$ H-NS, but

10 does not bind DNA and therefore interferes with H-NS mediated transcriptional

11 repression resulting from the formation of higher-order DNA-protein complexes

12 (Ueguchi et al., 1996). This observation is consistent with the reported finding that 13 expression of hns mutant G113D induces transcription from Pcas in wt E. coli (Pul et 14 al., 2010).

When plaque assays were performed in $E$. coli $\mathrm{J} 3$ over-expressing leu $O$ from a

16 plasmid, a $\sim 6$ fold reduced sensitivity to phage $\lambda_{\text {vir }}$ infection was observed (Fig. $5 B$ ),

17 demonstrating that LeuO activates CRISPR-based defense in E. coli. A 3-fold reduced 18 sensitivity was observed when leuO expression was not induced, probably due to 19 leakage from the Ptac promoter. When E. coli $\mathrm{J} 3$ cells were grown to stationary phase 20 in rich 2 YT medium, an increased resistance level was observed with turbid and very 21 small plaques in the leuO over-expressing strains containing a targeting CRISPR (data 22 not shown), whereas plaques in the same strain containing a non-targeting CRISPR 23 were clear and of normal size. Although cas3 gene expression was not strongly 24 induced when LeuO was expressed from a plasmid (Table 1 and Fig. 1B), the 25 expression of cas 3 was not a limiting factor for resistance, since introduction of a cas 3 
1 expression plasmid into $E$. coli $\mathrm{J} 3$ expressing leu $O$ did not lead to elevated resistance 2 levels (Fig. 5B).

When a plasmid expressing casABCDE12 was introduced in E. coli $\mathrm{J} 3$, a 2.5-

4 fold reduced sensitivity to phage infection was observed (Fig. 5C), which was not

5 observed when a CRISPR expression vector containing spacer J3 or a plasmid

6 encoding cas3 was introduced (Fig. 5C), indicating that expression of the genes encoding Cascade (cas $A B C D E$ ) is limiting for CRISPR-based defense in wt E. coli .

\section{Discussion}

The type E CRISPR/Cas system (Cse (Haft et al., 2005)) is present in many

11 proteobacteria and in some actinobacteria, firmicutes and methanogenic archaea. A

12 recent analysis of a collection of natural isolates shows that this CRISPR/Cas subtype 13 occurs in approximately $60 \%$ of the E. coli strains (Diez-Villasenor et al., 2010). The 14 study presented here provides experimental evidence for regulation of the type $\mathrm{E}$ 15 CRISPR/Cas system in E. coli K12 by the antagonists H-NS and LeuO. These 16 antagonistic DNA-binding proteins regulate the expression of several genes in E. coli, 17 such as the $b g l$ operon (utilization of $\beta$-glucosides) (Ueguchi et al., 1998), the $y j j Q$ $18 \mathrm{bglJ}$ operon (virulence factor and activator of $b g l$, respectively) (Stratmann et al., 19 2008) and the Salmonella enterica Serovar Typhi ompS1 gene (outer membrane 20 protein and pathogenicity determinant) (De la Cruz et al., 2007).

We demonstrate that relieving H-NS-mediated repression of cas gene 22 transcription is required for CRISPR-based immunity and that derepression is 23 mediated by LeuO through direct binding of DNA sequences upstream of casA. The 24 EMSA and footprint results (Fig. 3) support the finding that elevated amounts of 25 LeuO counteract H-NS-mediated repression of casABCDE12 in vivo. Moreover, these 
1 data indicate that LeuO-induced activation of transcription from the casA promoter

2 (Pcas) does not simply result from a displacement of bound H-NS, since LeuO cannot

3 facilitate the binding of RNA polymerase when H-NS is pre-bound. Instead, LeuO

4 abrogates the cooperative spreading of H-NS upon binding to the cas A promoter 5 region.

6 Interestingly, the transcript levels of the casABCDE12 operon were higher in 7 cells expressing leuO than in hns knockout strains (Fig. 1B), suggesting that either

8 LeuO functions as an enhancer of $\operatorname{cas} A B C D E 12$ transcription, or that derepression in

$9 \mathrm{~K} 12 \Delta h n s$ is incomplete. The latter could be due to additional repressors involved in 10 silencing casABCDE12, or due to functional redundancy between suppressors of gene 11 transcription. In particular, StpA has been reported to possess high binding affinity for 12 Pcas (Pul et al., 2010). Although a K12 $\Delta$ stpA strain showed similar cas gene 13 transcript levels as a $w t$ K12 strain (Pul et al., 2010) it cannot be excluded that StpAmediated repression of cas gene transcription takes place in the absence of H-NS. Cells expressing leuO showed higher resistance levels compared to hns

16 knockout strains, due to the higher expression of the cas genes and higher abundance 17 of mature crRNA (Fig. 1B and Fig. 2BC). Compared to the CRISPR-based resistance 18 levels to phage infection observed in Streptococcus thermophilus (Barrangou et al., 19 2007) or E. coli BL21-AI over-expressing the cas genes and the CRISPR (Brouns et $a l ., 2008)$, the resistance levels of wt E. coli over-expressing leuO are relatively low.

21 However, at present it is unknown whether a similar level of CRISPR-based immunity 22 can be reached by wt E. coli, and if it can, under what conditions.

Although we were able to show that CRISPR-based immunity is activated by 24 overproducing LeuO, the natural growth conditions that induce CRISPR-based defense are still unknown. Our experiments show that a genomic anti-Lambda spacer 
1 alone does not provide resistance to phage infection in wt E. coli due to the absence of

2 Cascade. We speculate that leuO expression levels under laboratory growth conditions

3 are too low to induce derepression Pcas, and that phage exposure itself does not

4 activate CRISPR-defense. Unaltered expression of leuO and the cas genes was also

5 observed during infection with bacteriophage PRD1 (Poranen et al., 2006).

6 Since H-NS is known to bind DNA of incoming phage or plasmid directly

7 (Navarre et al., 2006; Navarre et al., 2007) this might result in redistribution of H-NS

8 (Dillon et al., 2010; Doyle et al., 2007), allowing expression of the Cascade genes due

9 to decreased local concentrations of the repressor. As leuO expression is negatively

10 regulated by H-NS and positively by LeuO itself (Chen et al., 2005; Hommais et al.,

11 2001), this would further amplify the activating signal for cas gene transcription. Interestingly, leu $O$ expression levels are induced by the alarmone guanosine tetraphosphate (ppGpp) (Chen et al., 2001; Fang et al., 2000; Majumder et al., 2001). ppGpp is involved in stress signaling cascades leading to the stringent response under nutrient limiting conditions. Since these conditions slow down phage proliferation 16 dramatically (Schrader et al., 1997), bacterial cells may then stand a better chance of surviving phage encounters, hence inducing CRISPR-based defense may be more beneficial. However, induction of the stringent response by amino-acid starvation, e.g. by serine hydroxamate (Tosa and Pizer, 1971) neither increased the transcription from Pcas nor the formation of mature crRNA (data not shown). Although under laboratory

21 conditions CRISPR-based defense is suppressed, the diversity in spacer content in natural isolates of E. coli strongly suggests that the CRISPR/Cas system as a whole is active and functional in natural ecosystems (Diez-Villasenor et al., 2010). In an independent parallel study, it has been shown that an E. coli hns 
1 (Pougach et al., in press), in agreement with the data presented here. It seems that the

$2 \Delta h n s$ strain containing the T3 spacer used in (Pougach et al., in press), shows higher

3 levels of resistance than the $\Delta h n s$ strain containing the $\mathrm{J} 3$ spacer that was used in this

4 study. The T3 spacer has originally been described (Brouns et al., 2008) as the spacer

5 that confers the highest level of immunity of 8 different spacers tested. In BL21-AI

6 over-expressing the casABCDE and cas3 genes together with either the T3 CRISPR

7 or the J3 CRISPR showed that the T3 CRISPR provides 10-fold more resistance (data

8 not shown), indicating that the observed difference in immunity between (Pougach et

9 al., in press) and this study is most likely resulting from a difference in the efficiency 10 of the spacers used.

11 Although a number of studies involving H-NS and LeuO have been carried out

12 in E. coli and S. enterica (Hernandez-Lucas et al., 2008; Hommais et al., 2001;

13 Lucchini et al., 2006; Navarre et al., 2006; Shimada et al., 2009), the outcome of 14 these studies has never been interpreted in the light of CRISPR-based defense. Based 15 on these genome-wide analyses we propose that the expression of the type $\mathrm{E}$ (Cse) cas 16 genes from Salmonella enterica are likely to be regulated by H-NS and LeuO as well. 17 For instance, in S. enterica Serovar Typhi transcription of casA (STY3070) appears to 18 be affected by H-NS and LeuO (Hernandez-Lucas et al., 2008), despite the poor 19 conservation of the intergenic region between the divergently oriented cas 3 and cas $A$ 20 genes in this strain. In S. enterica Serovar Typhimurium strain LT2 H-NS binding 21 sites were found encompassing the translation start site of the cas3 gene (Lucchini et $22 a l ., 2006)$. Another study showed that in this strain the transcription of cas3, casB, 23 cas $C$ and $c a s D$ is elevated in the absence of H-NS (Navarre et al., 2006). Perhaps the 24 cas genes are controlled by a single promoter in this strain, since the intergenic region between cas 3 and cas $A$ is only 12 nucleotides in length. 
1 Altogether, this study provides evidence that the type E CRISPR/Cas system

2 in E. coli is regulated by the antagonists H-NS and LeuO, and we propose that this 3 regulatory mechanism is conserved in S. enterica as well. The upcoming challenge

4 will be to identify conditions that activate this sophisticated defense system to allow 5 defense against invasion by foreign DNA. 


\section{Experimental procedures}

\section{Strains}

3 The wildtype E. coli K12 W3110 (BW25113) strain and the E. coli K12 W3110

4 derivative $\Delta h n s$ (JW1225) and $\Delta$ casA (JW2730) from the KEIO collection (Baba et al., 5 2008), supplied by the American Type Culture Collection (ATCC), and E. coli K12

6 MC4100 (Peters et al., 2003) derivative $\Delta h n s$ (PD32) (Dersch et al., 1993) were used 7 throughout the study.

9 Gene cloning and recombination

10 A synthetic recombination cassette was designed corresponding to $400 \mathrm{bp}$ flanking 11 regions on each side of the CRISPR I locus separated by a kanamycin resistance gene 12 flanked by FRT-sites (GAAGTTCCTATACTTTCTAGAGAATAGGAACTTC). The 13 construct contained a PstI site followed by $400 \mathrm{nt}$ of the CRISPR I upstream region of 14 the E. coli K12 W3110 genome (2875875-2876274), followed by a NcoI site, then the 15 sequence AAACAAAGAATT, a $K p n I$ site, followed by an FRT-site, a $S p h I$ site, a 16 kanamycin resistance gene with a sequence corresponding to pJJDuet30 (2186-1276), 17 a XhoI site, an FRT site, a NotI site, and 395 nt of the CRISPR I downstream region of 18 the E. coli K12 W3110 genome (2877225-2877619) (GeneArt AG, Regensburg, 19 Germany). A synthetic CRISPR sequence including leader sequence containing 7 20 spacers and 8 repeats was used (Table S1) (Geneart AG, Regensburg, Germany). This 21 synthetic CRISPR was cloned between the flanking regions using the $N c o$ I and $K p n I$ 22 sites (Fig. S3). The NcoI and EcoRI sites in the leader and second spacer were used to 23 exchange the first spacer sequence of the CRISPR; the constructs created were named $24 \mathrm{~J} 3$ and R44 (Table S1). The other spacers in the CRISPR were sequences with no 25 homology to phage Lambda. These constructs were used as recombination cassettes to 
1 replace the existing CRISPR I locus in the E. coli $\mathrm{K} 12 \mathrm{~W} 3110$ genome, following a

2 protocol described elsewhere (Datsenko and Wanner, 2000), with minor modifications.

3 For recombination, the sequences were PCR-amplified using primers BG3017 and

4 BG3019 (Table S2) with high fidelity $p f u$-turbo polymerase and transformed by

5 electroporation into E. coli K12 W3110 containing pKD46, kindly provided by the

6 ATCC. Transformants were grown at $30^{\circ} \mathrm{C}$ and plated on LB-Agar supplemented with

7 kanamycin $\left(50 \mu \mathrm{g} \mathrm{ml}^{-1}\right)$. The pKD46 plasmid has a temperature sensitive origin of

8 replication, and was removed through growth at $37^{\circ} \mathrm{C}$ (Datsenko and Wanner, 2000).

9 Recombination was validated by PCR and sequencing. The antibiotic resistance

10 cassette was removed using Flp recombinase encoded on plasmid pCP20, and

11 subsequent growth at $37^{\circ} \mathrm{C}$, as described (Datsenko and Wanner, 2000). The $\Delta l e u O$

12 mutant was constructed with the $\lambda$ red-gam system using oligonucleotides T209 and

13 T210 (Table S2), as described (Datsenko and Wanner, 2000). After deletion of leuO

14 the resistance cassette used for selection was removed using Flp recombinase encoded

15 on plasmid pCP20 (Datsenko and Wanner, 2000).

\section{Plasmids and Vectors}

18 Plasmid pWUR607 $\left(\right.$ Tet $\left.^{\mathrm{R}}\right)$ contains the casABCDE12 operon, which was PCR-

19 amplified from E. coli K12 MG1655 genomic DNA using primers BG2173 and

20 BG2174 (Table S2), and cloned into vector pACYC184 using the restriction sites

21 EcoRI and NcoI. Plasmid pWUR608 $\left(\mathrm{Cam}^{\mathrm{R}}\right)$ was constructed by cloning a cas3

22 amplicon generated with primers BG2171 and BG2172 (Table S2) into pACYC184

23 using the restriction enzymes BamHI and SphI. In the experiments where a CRISPR

24 was introduced on a plasmid, the pACYCduet-1 vector $\left(\mathrm{Cam}^{\mathrm{R}}\right)$ (Novagen) was used,

25 using the $N c o$ I and Acc65I restriction sites. pWUR477 containing the non-targeting 
1 CRISPR (N) was described previously (Brouns et al., 2008). Expression of the

2 CRISPR from this plasmid in K12 was under control of the leader sequence that

3 contains the CRISPR I promoter (Pul et al., 2010). pWUR564 is a derivative of

4 pWUR477 that has the NcoI-EcoRI fragment (containing the leader sequence up to

5 half of the second spacer) replaced with the NcoI-EcoRI fragment of construct J3

6 (Table S1). For expression of wt hns and $h n s^{\mathrm{G} 113 \mathrm{D}}$ the previously described pHOP11

7 and pHM52 plasmids were used, respectively (Pul et al., 2010). The pCA24N plasmid

8 from ASKA(-) clone JW0075 encodes leuO behind an PT5/lac promoter (IPTG

9 inducible). pKEDR13, encoding leuO behind a Ptac promoter (IPTG inducible), and

10 the control vector pKESK22 were described earlier (Madhusudan et al., 2005;

11 Stratmann et al., 2008). The IPTG inducible leuO expression plasmid pNH41 was

12 constructed by cloning the leuO amplicon, generated using primers $\mathrm{NH} 329$ and

$13 \mathrm{NH} 330$ (Table S2), into the $2.2 \mathrm{~kb}$ XbaI fragment of pZE12-luc, following a

14 previously published protocol (Urban and Vogel, 2007). Plasmid pNH6 contains the

15 casABCDE operon (PCR amplified with pre-phosphorylated primer NH193 and

16 primer NH194 (Table S2)) inserted by blunt end and EcoRI cloning into vector

17 pCU01 (pBAD-TOPO vector derivative), as described (Unoson and Wagner, 2008).

18 Plasmid pUC18-IGLB was described before (Pul et al., 2010).

\section{Microarray}

21 E. coli $\mathrm{K} 12 \mathrm{MG} 1655$ was transformed with plasmid pKEDR13 ( $\operatorname{Kan}^{\mathrm{R}}$ lacl ${ }^{q} \mathrm{Ptac}$ leuO)

22 (Stratmann et al., 2008) for expression of LeuO or with control vector pKESK22

$23\left(\operatorname{Kan}^{\mathrm{R}} \operatorname{lacl}^{\mathrm{q}} \mathrm{Ptac}\right)$. Exponential cultures were inoculated from fresh overnight cultures

24 to an $\mathrm{OD}_{600}$ of 0.1 in LB supplemented with $25 \mu \mathrm{g} \mathrm{ml}^{-1}$ kanamycin. IPTG was added 25 after $30 \mathrm{~min}$ of growth to a final concentration of $1 \mathrm{mM}$. After additional 60 minutes 
1 the bacteria were harvested using Qiagen RNAprotect and used for RNA isolation

2 using the Qiagen RNeasy MiniKit system. In brief, $1 \mathrm{ml}$ of each culture $\left(\mathrm{OD}_{600}\right.$

3 between 0.5 and 0.6 ) was used and processed according to the manufacturer's

4 instructions including an on-column DNase I treatment. RNA quality was assayed by

5 denaturing urea-PAGE and by measuring the ratio of absorption at 260/280 $\mathrm{nm}$ in a

6 GeneQuant II spectrophotometer (Amersham). RNA concentration was determined by

7 measuring UV light absorption at $260 \mathrm{~nm}$. The procedure was carried out four times

8 with independent clones.

Synthesis of cDNA (and cRNA) and hybridization of Affymetrix GeneChip®

10 E. coli Genome 2.0 microarrays was carried out according to the manufacturer's

11 instructions. In total, four independent RNA samples of each group (wildtype, leuO

12 expressing and leuO deficient strains) were used. Data analysis was performed using

13 Affymetrix Software. Fluorescence values were normalized to the GeneChip standard

14 reference probes. Differential expression values were calculated as fold-change of

15 leuO expressing samples compared to samples of LeuO-deficient control strains.

\section{qPCR analysis of gene expression}

qPCR analysis of cas gene transcript abundance was performed on cDNA synthesized using High Capacity Reverse Transcription Kit (Applied Biosystems) from RNA extracted by the hot-phenol method (Blomberg et al., 1990) and DNaseI-treated using

21 Turbo DNA-free kit (Ambion). $10 \mathrm{ml}$ samples for RNA extraction were taken at $\mathrm{OD}_{600} \sim 0.5$ from E. coli $\mathrm{W} 3110$, E. coli $\mathrm{W} 3110$ carrying pCA24N $(l e u O)$ and E. coli $\Delta h n s$ (JW1225-2). When LeuO expression was induced, samples were taken $30 \mathrm{~min}$

24 after addition of $0.5 \mathrm{mM}$ IPTG. The qPCR reactions were performed using Power 25 SYBR green PCR master mix (Applied Biosystems) according to manufacturer's 
1 instructions, and primers were designed using Primer Express 3.0 (Applied

2 Biosystems). For the complete list of primers used see Table S3. As an internal

3 control two primer pairs were designed against casA. The PCR reactions were

4 performed on a 7300 Real Time PCR System (Applied Biosystems) and analyzed

5 using 7300 System SDS Software 1.3 (Applied Biosystems). Fold-change of cas gene

6 transcription was calculated using the relative quantification method with tmRNA as

7 endogenous control and E. coli W3110 cas gene transcript abundance as calibrators.

8 All PCR reactions were performed in six replicates. Control PCRs without template or

9 without cDNA (produced by standard cDNA synthesis but excluding reverse

10 transcriptase) were performed to monitor general contamination levels and genomic

11 DNA contamination of RNA extracts, respectively.

\section{Northern Blotting}

14 Total RNA was extracted at the $\mathrm{OD}_{600}$ indicated using TRIZOL reagent (Invitrogen)

15 according to the manufacturer's protocol. Expression of casABCDE from pNH6 was

16 induced at an $\mathrm{OD}_{600}$ of 0.5 by adding $0.2 \%$ of arabinose for $15 \mathrm{~min} .10 \mu \mathrm{g}$ of total

17 RNA was denatured at $95^{\circ} \mathrm{C}$ with an equal volume of formamide loading dye, FD

18 (90\% formamide, $15 \mathrm{mM}$ EDTA, $0.05 \%$ bromophenol blue and $0.05 \%$ xylene cyanol),

19 and subsequently separated on an $8 \%$ denaturing polyacrylamide gel. A ${ }^{32} \mathrm{P}$-labeled

20 pUC19 DNA/MspI ladder (Fermentas) was used as size marker. The RNA was

21 electrotransferred to Nylon $\mathrm{N}+$ membranes (GE Healthcare) at $10 \mathrm{~V}$ for $15 \mathrm{~h}$. Transfer

22 was performed in a BIORAD blotting chamber in 1 XTBE buffer at $4^{\circ} \mathrm{C}$ followed by

23 drying of the membrane and UV-crosslinking. Prehybridization was carried out for 2-

$24 \quad 4 \mathrm{~h}$ at $42^{\circ} \mathrm{C}$ in $15 \mathrm{ml}$ prehybridization buffer (5x SSC, 5x Dernhardt, $0.05 \mathrm{M}$ sodium

25 phosphate $\mathrm{pH} 6.7,1 \%$ dextran sulphate, $0.1 \%$ SDS) together with $75 \mu 1$ herring sperm 
1 DNA $\left(20 \mathrm{mg} \mathrm{ml}^{-1}\right)$. Hybridization was carried out overnight at $42^{\circ} \mathrm{C}$ in the same

2 buffer lacking herring sperm DNA but containing $\left[\gamma_{-}{ }^{32} \mathrm{P}\right]$-ATP-labeled 3 oligonucleotide probe NH30 (Table S2) specific for spacer 2 of the CRISPR1 locus.

4 The probe was labeled with $\left[\gamma_{-}{ }^{32} \mathrm{P}\right] \mathrm{ATP}$ (40 pmol DNA, 10x kinase buffer, T4

5 polynucleotide kinase (PNK, Ambion), $\left.\left[\gamma^{32} \mathrm{P}\right] \mathrm{ATP}\right)$ by incubation at $37^{\circ} \mathrm{C}$ for $45 \mathrm{~min}$.

6 Prior to hybridization, the probe was purified over a G-50 column (GE Healthcare).

7 Membranes were washed once for $20 \mathrm{~min}$ at $60^{\circ} \mathrm{C}$ in $2 \mathrm{xSSC}, 0.5 \%$ SDS and once for 820 min in $0.5 x$ SSC, $0.5 \%$ SDS. Signals were quantified in a Molecular Dynamics 9 PhosphorImager model 400S with ImageQuant software version 4.2a (Molecular 10 Dynamics).

\section{Electrophoretic Mobility Shift Assay}

13 E. coli RNAP, LeuO and H-NS were purified according to published procedures (Pul 14 et al., 2010; Stratmann et al., 2008). The IGLB fragment (position -1 to -414 , relative 15 to the first nucleotide of the casA (ygcL) start codon) was obtained by EcoRI/HincII or 16 BamHI/SacI digestion of plasmid pUC18-IGLB. Purified DNA fragments were end17 labelled by Klenow (Promega) and $\left[\alpha-{ }^{32} \mathrm{P}\right]-\mathrm{dATP}$. Binding reactions with the 18 indicated amounts of protein were performed in $50 \mathrm{mM}$ Tris- $\mathrm{HCl}, \mathrm{pH} 7.4,70 \mathrm{mM}$ $19 \mathrm{KCl}, 15 \mathrm{mM} \mathrm{NaCl}, 1 \mathrm{mM}$ EDTA, $10 \mathrm{mM} \beta$-mercaptoethanol at a final heparin 20 concentration of $20 \mathrm{ng} \mu \mathrm{l}^{-1}$. Complexes were separated on native $5 \%(\mathrm{w} / \mathrm{v})$ 21 polyacrylamide gels and visualized by autoradiography as described (Pul et al., 2010).

\section{Footprint analyses}

24 DNase I footprinting of free DNA and DNA-protein complexes was performed as described (Pul et al., 2010). Formation of open RNAP-promoter complexes was 
1 analyzed by $\mathrm{KMnO}_{4}$ modification of single-stranded nucleotides within the

2 transcription bubble. $40 \mu \mathrm{l}$ RNAP-DNA complexes were treated with $160 \mathrm{mM}$

$3 \mathrm{KMnO}_{4}$ for $2 \mathrm{~min}$ at $30^{\circ} \mathrm{C}$. The reaction was stopped by addition of $5.3 \mu \mathrm{l} \beta$ -

$4 \quad$ mercaptoethanol and $5.3 \mu \mathrm{l} 500 \mathrm{mM}$ EDTA and the samples were ethanol precipitated

5 after phenol/chloroform extraction. Pellets were dissolved in $10 \%$ piperidine and

6 incubated at $90^{\circ} \mathrm{C}$ for $30 \mathrm{~min}$. After two rounds of washing with distilled water

7 followed by lyophilizing, the pellets were dissolved in $50 \mu \mathrm{l}$ distilled water and

8 precipitated with ethanol. Cleavage products were separated on $10 \%$ denaturing

9 polyacrylamid gels and visualized by autoradiography. The following protocol was

10 used in footprint experiments with more than one protein: LeuO or the protein-free

11 buffer, and H-NS or the respective buffer, were incubated with the template DNA for

125 min at $30^{\circ} \mathrm{C}$. Next RNAP or the RNAP dilution buffer was added and incubated for

13 another $10 \mathrm{~min}$. Finally heparin was added to a final concentration of $200 \mathrm{ng} \mu \mathrm{l}^{-1}$ with

14 a further incubation at $30^{\circ} \mathrm{C}$ for $5 \mathrm{~min}$. An aliquot of this solution was loaded on a

15 native gel to verify complex formation and the remaining solution was used for the 16 different footprint experiments.

\section{Primer extension analysis}

19 Primer extension reactions with $25 \mu \mathrm{g}$ total RNA hybridized to a radiolabeled specific 20 cas primer oligonucleotide (5'-ATACAATTAATCTATACATATATTAAGATG-3')

21 were performed with AMV reverse transcriptase (Promega) as described (Afflerbach 22 et al., 1998).

\section{Phage Lambda infection studies}


1 Host sensitivity to phage infection was tested using a virulent phage Lambda $\left(\lambda_{\text {vir }}\right)$, as

2 before (Brouns et al., 2008). The host strains for infection were either wt E. coli K12

$3 \mathrm{~W} 3110$, E. coli K12 W3110 $\Delta h n s$, or the engineered E. coli K12 W3110 strains (E.

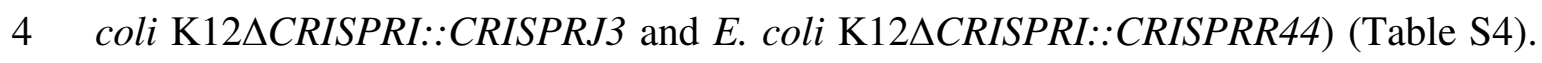

5 The sensitivity of the host to infection was calculated as the efficiency of plaquing

6 (the plaque count ratio of a strain containing an anti-Lambda CRISPR to that of the

7 strain containing an non-targeting CRISPR) (Brouns et al., 2008).

8 


\section{Acknowledgements}

2 This work was financially supported by a Veni grant to S.J.J.B. (863.08.014) and a

3 Vici grant to J.v.d.O. (865.05.001) from the Dutch Organization for Scientific

4 Research (Nederlandse Organisatie voor Wetenschappelijk Onderzoek). E.R.W. was

5 financially supported by Spinoza resources awarded to Willem M. de Vos. Ü.P. was

6 supported by the Deutsche Forschungsgemeinschaft PU435/1-1. N.H. was supported

7 by a postdoc fellowship from the Swedish Research Council (Vetenskapsrådet). M.L.

8 was supported by the Wenner-Gren Foundations. T.S. and K.S. were supported by the

9 Deutsche Forschungsgemeinschaft Schn 371 / 10-1. A.R. and E.G.H.W. were

10 supported by the Swedish Research Council. 


\section{$1 \quad$ References}

2 Afflerbach, H., Schroder, O., and Wagner, R. (1998) Effects of the Escherichia coli DNA-binding protein H-NS on rRNA synthesis in vivo. Mol Microbiol 28: 641-653.

Baba, T., Huan, H.C., Datsenko, K., Wanner, B.L., and Mori, H. (2008) The applications of systematic in-frame, single-gene knockout mutant collection of Escherichia coli K-12. Methods Mol Biol 416: 183-194.

Barrangou, R., Fremaux, C., Deveau, H., Richards, M., Boyaval, P., Moineau, S., Romero, D.A., and Horvath, P. (2007) CRISPR provides acquired resistance against viruses in prokaryotes. Science 315: 1709-1712.

Blomberg, P., Wagner, E.G., and Nordstrom, K. (1990) Control of replication of plasmid R1: the duplex between the antisense RNA, CopA, and its target, CopT, is processed specifically in vivo and in vitro by RNase III. Embo J 9: 2331-2340.

Bolotin, A., Ouinquis, B., Sorokin, A., and Ehrlich, S.D. (2005) Clustered regularly interspaced short palindrome repeats (CRISPRs) have spacers of extrachromosomal origin. Microbiology 151: 2551-2561.

Bouffartigues, E., Buckle, M., Badaut, C., Travers, A., and Rimsky, S. (2007) HNS cooperative binding to high-affinity sites in a regulatory element results in transcriptional silencing. Nat Struct Mol Biol 14: 441-448.

Brouns, S.J.J., Jore, M.M., Lundgren, M., Westra, E.R., Slijkhuis, R.J.H., Snijders, A.P.L., Dickman, M.J., Makarova, K.S., Koonin, E.V., and van der Oost, J. (2008) Small CRISPR RNAs guide antiviral defense in prokaryotes. Science 321: 960-964. 
1 Carte, J., Wang, R.Y., Li, H., Terns, R.M., and Terns, M.P. (2008) Cas6 is an endoribonuclease that generates guide RNAs for invader defense in prokaryotes. Genes Dev 22: 3489-3496.

Chen, C.C., Fang, M., Majumder, A., and Wu, H.Y. (2001) A 72-base pair ATrich DNA sequence element functions as a bacterial gene silencer. $J$ Biol Chem 276: 9478-9485.

Chen, C.C., Chou, M.Y., Huang, C.H., Majumder, A., and Wu, H.Y. (2005) A cis-spreading nucleoprotein filament is responsible for the gene silencing activity found in the promoter relay mechanism. J Biol Chem 280: 51015112.

Chen, C.C., and Wu, H.Y. (2005) LeuO protein delimits the transcriptionally active and repressive domains on the bacterial chromosome. $J$ Biol Chem 280: 15111-15121.

Dame, R.T., Luijsterburg, M.S., Krin, E., Bertin, P.N., Wagner, R., and Wuite, G.J. (2005) DNA bridging: a property shared among H-NS-like proteins. J Bacteriol 187: 1845-1848.

Datsenko, K.A., and Wanner, B.L. (2000) One-step inactivation of chromosomal genes in Escherichia coli K-12 using PCR products. Proc Natl Acad Sci U $S$ A 97: 6640-6645.

De la Cruz, M.A., Fernandez-Mora, M., Guadarrama, C., Flores-Valdez, M.A., Bustamante, V.H., Vazquez, A., and Calva, E. (2007) LeuO antagonizes H-NS and StpA-dependent repression in Salmonella enterica ompS1. Mol Microbiol 66: 727-743. 
1 Dersch, P., Schmidt, K., and Bremer, E. (1993) Synthesis of the Escherichia coli K-12 nucleoid-associated DNA-binding protein H-NS is subjected to growth-phase control and autoregulation. Mol Microbiol 8: 875-889.

Diez-Villasenor, C., Almendros, C., Garcia-Martinez, J., and Mojica, F.J. (2010) Diversity of CRISPR loci in Escherichia coli. Microbiology 156: 1351-1361.

Dillon, S.C., Cameron, A.D., Hokamp, K., Lucchini, S., Hinton, J.C., and Dorman, C.J. (2010) Genome-wide analysis of the H-NS and Sfh regulatory networks in Salmonella Typhimurium identifies a plasmidencoded transcription silencing mechanism. Mol Microbiol. 76: 1250-1265.

Doyle, M., Fookes, M., Ivens, A., Mangan, M.W., Wain, J., and Dorman, C.J. (2007) An H-NS-like stealth protein aids horizontal DNA transmission in bacteria. Science 315: 251-252.

Fang, M., Majumder, A., Tsai, K.J., and Wu, H.Y. (2000) ppGpp-dependent leuO expression in bacteria under stress. Biochem Biophys Res Commun 276: 64-70.

Haft, D.H., Selengut, J., Mongodin, E.F., and Nelson, K.E. (2005) A guild of 45 CRISPR-associated (Cas) protein families and multiple CRISPR/Cas subtypes exist in prokaryotic genomes. Plos Comp Biol 1: 474-483.

Hernandez-Lucas, I., Gallego-Hernandez, A.L., Encarnacion, S., FernandezMora, M., Martinez-Batallar, A.G., Salgado, H., Oropeza, R., and Calva, E. (2008) The LysR-type transcriptional regulator LeuO controls expression of several genes in Salmonella enterica serovar typhi. $J$ Bacteriol 190: 1658-1670. 
1 Hertzberg, K.M., Gemmill, R., Jones, J., and Calvo, J.M. (1980) Cloning of an EcoRI-generated fragment of the leucine operon of Salmonella typhimurium. Gene 8: 135-152.

Hommais, F., Krin, E., Laurent-Winter, C., Soutourina, O., Malpertuy, A., Le Caer, J.P., Danchin, A., and Bertin, P. (2001) Large-scale monitoring of pleiotropic regulation of gene expression by the prokaryotic nucleoidassociated protein, H-NS. Mol Microbiol 40: 20-36.

Horvath, P., and Barrangou, R. (2010) CRISPR/Cas, the Immune System of Bacteria and Archaea. Science 327: 167-170.

Hyman, P., and Abedon, S.T. (2010) Bacteriophage Host Range and Bacterial Resistance. Adv Appl Microbiol 70C: 217-248.

Ishino, Y., Shinagawa, H., Makino, K., Amemura, M., and Nakata, A. (1987) Nucleotide sequence of the iap gene, responsible for alkaline phosphatase isozyme conversion in Escherichia coli, and identification of the gene product. J Bacteriol 169: 5429-5433.

Jansen, R., van Embden, J.D.A., Gaastra, W., and Schouls, L.M. (2002) Identification of genes that are associated with DNA repeats in prokaryotes. Mol Microbiol 43: 1565-1575.

Karginov, F.V., and Hannon, G.J. (2010) The CRISPR System: Small RNAGuided Defense in Bacteria and Archaea. Mol Cell 37: 7-19.

Klauck, E., Bohringer, J., and Hengge-Aronis, R. (1997) The LysR-like regulator LeuO in Escherichia coli is involved in the translational regulation of rpoS by affecting the expression of the small regulatory DsrA-RNA. Mol Microbiol 25: 559-569. 
1 Kunin, V., Sorek, R., and Hugenholtz, P. (2007) Evolutionary conservation of sequence and secondary structures in CRISPR repeats. Genome Biology 8. Labrie, S.J., Samson, J.E., and Moineau, S. (2010) Bacteriophage resistance mechanisms. Nat Rev Microbiol 8: 317-327.

Lang, B., Blot, N., Bouffartigues, E., Buckle, M., Geertz, M., Gualerzi, C.O., Mavathur, R., Muskhelishvili, G., Pon, C.L., Rimsky, S., Stella, S., Babu, M.M., and Travers, A. (2007) High-affinity DNA binding sites for H-NS provide a molecular basis for selective silencing within proteobacterial genomes. Nucleic Acids Res 35: 6330-6337.

Lawley, T.D., Chan, K., Thompson, L.J., Kim, C.C., Govoni, G.R., and Monack, D.M. (2006) Genome-wide screen for Salmonella genes required for longterm systemic infection of the mouse. PLoS Pathog 2: e11.

Liu, Y., Chen, H., Kenney, L.J., and Yan, J. (2010) A divalent switch drives HNS/DNA-binding conformations between stiffening and bridging modes. Genes Dev 24: 339-344.

Lucchini, S., Rowley, G., Goldberg, M.D., Hurd, D., Harrison, M., and Hinton, J.C. (2006) H-NS mediates the silencing of laterally acquired genes in bacteria. PLoS Pathog 2: e81.

Maddocks, S.E., and Oyston, P.C. (2008) Structure and function of the LysRtype transcriptional regulator (LTTR) family proteins. Microbiology 154: 3609-3623.

Madhusudan, S., Paukner, A., Klingen, Y., and Schnetz, K. (2005) Independent regulation of H-NS-mediated silencing of the bgl operon at two levels: upstream by BglJ and LeuO and downstream by DnaKJ. Microbiology 151: 3349-3359. 
1 Majumder, A., Fang, M., Tsai, K.J., Ueguchi, C., Mizuno, T., and Wu, H.Y. (2001) LeuO expression in response to starvation for branched-chain amino acids. J Biol Chem 276: 19046-19051.

Marraffini, L.A., and Sontheimer, E.J. (2008) CRISPR Interference Limits Horizontal Gene Transfer in Staphylococci by Targeting DNA. Science 322: 1843-1845.

Marraffini, L.A., and Sontheimer, E.J. (2010) CRISPR interference: RNAdirected adaptive immunity in bacteria and archaea. Nat Rev Genetics 11: 181-190.

Mojica, F.J., Diez-Villasenor, C., Soria, E., and Juez, G. (2000) Biological significance of a family of regularly spaced repeats in the genomes of Archaea, Bacteria and mitochondria. Mol Microbiol 36: 244-246.

Mojica, F.J.M., Diez-Villasenor, C., Garcia-Martinez, J., and Soria, E. (2005) Intervening sequences of regularly spaced prokaryotic repeats derive from foreign genetic elements. J Mol Evol 60: 174-182.

Navarre, W.W., Porwollik, S., Wang, Y., McClelland, M., Rosen, H., Libby, S.J., and Fang, F.C. (2006) Selective silencing of foreign DNA with low GC content by the H-NS protein in Salmonella. Science 313: 236-238.

Navarre, W.W., McClelland, M., Libby, S.J., and Fang, F.C. (2007) Silencing of xenogeneic DNA by H-NS-facilitation of lateral gene transfer in bacteria by a defense system that recognizes foreign DNA. Genes Dev 21: 14561471.

Oshima, T., Ishikawa, S., Kurokawa, K., Aiba, H., and Ogasawara, N. (2006) Escherichia coli histone-like protein H-NS preferentially binds to 
horizontally acquired DNA in association with RNA polymerase. DNA Res 13: 141-153.

Peters, J.E., Thate, T.E., and Craig, N.L. (2003) Definition of the Escherichia coli MC4100 genome by use of a DNA array. J Bacteriol 185: 2017-2021.

Poranen, M.M., Ravantti, J.J., Grahn, A.M., Gupta, R., Auvinen, P., and Bamford, D.H. (2006) Global changes in cellular gene expression during bacteriophage PRD1 infection. J Virol 80: 8081-8088.

Pourcel, C., Salvignol, G., and Vergnaud, G. (2005) CRISPR elements in Yersinia pestis acquire new repeats by preferential uptake of bacteriophage DNA, and provide additional tools for evolutionary studies. Microbiology 151: 653-663.

Pul, U., Wurm, R., Arslan, Z., Geissen, R., Hofmann, N., and Wagner, R. (2010) Identification and characterization of E. coli CRISPR-cas promoters and their silencing by H-NS. Mol Microbiol. 75: 1495-1512.

Schrader, H.S., Schrader, J.O., Walker, J.J., Wolf, T.A., Nickerson, K.W., and Kokjohn, T.A. (1997) Bacteriophage infection and multiplication occur in Pseudomonas aeruginosa starved for 5 years. Can J Microbiol 43: 11571163.

Shimada, T., Yamamoto, K., and Ishihama, A. (2009) Involvement of the Leucine Response Transcription Factor LeuO in Regulation of the Genes for Sulfa Drug Efflux. J Bacteriol 191: 4562-4571.

Stoebel, D.M., Free, A., and Dorman, C.J. (2008) Anti-silencing: overcoming HNS-mediated repression of transcription in Gram-negative enteric bacteria. Microbiology 154: 2533-2545. 
1 Stratmann, T., Madhusudan, S., and Schnetz, K. (2008) Regulation of the yjjQbglJ operon, encoding LuxR-type transcription factors, and the divergent yjjP gene by H-NS and LeuO. J Bacteriol 190: 926-935.

Tosa, T., and Pizer, L.I. (1971) Biochemical bases for the antimetabolite action of L-serine hydroxamate. J Bacteriol 106: 972-982.

Ueguchi, C., Suzuki, T., Yoshida, T., Tanaka, K., and Mizuno, T. (1996) Systematic mutational analysis revealing the functional domain organization of Escherichia coli nucleoid protein H-NS. J Mol Biol 263: 149-162.

Ueguchi, C., Ohta, T., Seto, C., Suzuki, T., and Mizuno, T. (1998) The leuO gene product has a latent ability to relieve bgl silencing in Escherichia coli. $J$ Bacteriol 180: 190-193.

Unoson, C., and Wagner, E.G. (2008) A small SOS-induced toxin is targeted against the inner membrane in Escherichia coli. Mol Microbiol 70: 258270.

Urban, J.H., and Vogel, J. (2007) Translational control and target recognition by Escherichia coli small RNAs in vivo. Nucleic Acids Res 35: 1018-1037.

van der Oost, J., Jore, M.M., Westra, E.R., Lundgren, M., and Brouns, S.J.J. (2009) CRISPR-based adaptive and heritable immunity in prokaryotes. Trends Biochem Sci 34: 401-407.

Vartak, N.B., Liu, L., Wang, B.M., and Berg, C.M. (1991) A functional leuABCD operon is required for leucine synthesis by the tyrosine-repressible transaminase in Escherichia coli K-12. J Bacteriol 173: 3864-3871. 


\section{$1 \quad$ Figure Legends}

2

3

4 LeuO and H-NS regulate cas gene expression. A) Schematic illustration of the

5 CRISPR/Cas locus in E. coli K12 that consists of 8 cas genes (cas3 (ygcB), casA

6 (ygcL or $c s e 1), \operatorname{casB}(y g c K$ or $c s e 2), \operatorname{cas} C$ (ygcJ or $c s e 4) \operatorname{cas} D$ (ygcI or cas $5 e$ ) casE

$7(y g c H$ or $c s e 3)$, cas1 $(y g b T)$ and cas2 $(y g b F))$ and a downstream CRISPR locus

8 containing 12 spacers and 13 repeats (CRISPR I). The cas3, anti-cas3 (anti-Pcas),

$9 \operatorname{casA}$ (Pcas) and CRISPR I promoter are indicated with an arrow (Pul et al., 2010). B)

10 qPCR analysis of cas gene transcript abundance in E. coli $\Delta h n s$ and E. coli W3110

11 expressing leuO (induced or non-uninduced). Fold changes are given as compared to

12 wt E. coli $\mathrm{W} 3110$ expression levels. Error bars indicate one standard deviation.

\section{Fig. 2}

15 Formation of mature crRNA. A) Northern analysis of total RNA from wt E. coli K12 16 and wt E. coli $\mathrm{K} 12+\operatorname{cas} A B C D E$ (pNH6) using the single stranded spacer sequence 17 NH30 (Table S2) as a probe. B) Northern analysis as in (A) of total RNA from E. coli $18 \mathrm{~K} 12 \Delta h n s$ and C) $w t$ E. coli $\mathrm{K} 12$ expressing leuO from a plasmid (pNH41) with an $19 \mathrm{OD}_{600}$ of $0.5,1$ and 3.0. M, size marker (pUC19/MspI ladder). E. coli K12 $\Delta$ casA 20 (JW2730) serves as a control and marker for mature crRNA.

$22 \quad$ Fig. 3

23 H-NS and LeuO binding to the DNA region upstream of casA (the IGLB fragment). A)

24 Electrophoretic Mobility Shift Assay (EMSA) of the IGLB fragment with LeuO and 
1 H-NS, either alone (lanes 5-7) or with pre-bound LeuO and subsequent addition of H-

2 NS (lanes 8-11) or pre-bound H-NS and subsequent addition of LeuO (lanes 12-15). B)

3 DNase I footprint of IGLB in the presence of either H-NS or LeuO or both. LeuO was

4 pre-incubated with the reaction mixture. The 2 main regions protected by LeuO are

5 indicated. The ladder indicates the IGLB coordinates relative to the casA start codon,

6 indicated in $\mathbf{C}$ ) the sequence and coordinates of IGLB, with the H-NS and LeuO

7 binding sites indicated with boxes. See also Fig. 4A for footprints showing the LeuO

8 binding region $\mathrm{I}$.

9

10 Fig. 4

11 Effects of LeuO and H-NS on RNA polymerase open complex formation at the IGLB

12 fragment. A) and B) show either DNase I (lanes 1-14) or $\mathrm{KMnO}_{4}$ (lanes 1'-14')

13 footprint analyses of the non-template strand of IGLB after binding of RNA 14 polymerase, H-NS or LeuO, either individually or in combination. The numbers 15 above the lanes indicate the order of addition of the respective proteins. The casA 16 promoter (Pcas) (I) and the anti-cas3 promoter (anti-Pcas) (II) are indicated. The 17 arrowheads indicate the nucleotides within open complexes at the promoter sites. C) 18 and D) show the binding of RNA polymerase, H-NS or LeuO, either individually or in 19 combination. C) shows Electrophoretic Mobility Shift Assays of the samples in (A) 20 and (B). The numbers above the lanes indicate the order of addition of the respective 21 proteins. D) shows Electrophoretic Mobility Shift Assays of the samples in (E). The 22 positions of the free DNA and complexed DNA are given on the left. The retardation 23 gels (C) and (D) are not standard retardation gels but controls for the footprint 24 complexes to see if no major decomposition has occurred. Because complexes are 25 kept at $30^{\circ} \mathrm{C}$ for some time under RNAP binding conditions these gels are sometimes 
1 different from standard retardation experiments (e.g. Fig. 3A). E) Shows a similar

2 analysis as in (A) and (B) for the template strand of IGLB (DNase I footprint lanes 1-

$38 ; \mathrm{KMnO}_{4}$ footprint lanes 1 '-8'). The protein concentrations used are $\mathrm{H}-\mathrm{NS}(1 \mu \mathrm{M})$,

$4 \quad$ LeuO $(1 \mu \mathrm{M})$ and RNA polymerase $(50 \mathrm{nM})$.

$6 \quad$ Fig. 5

7 Effect of H-NS and LeuO on CRISPR-based resistance in vivo. A) A synthetic 8 CRISPR with one spacer (J3) targeting phage Lambda on a plasmid (pWUR564) is

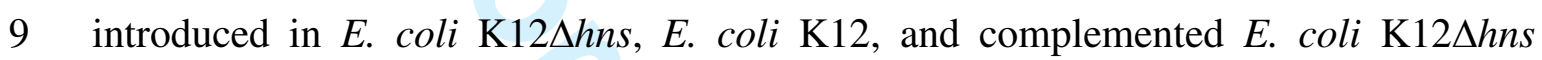
10 expressing hns from the pHOP11 plasmid. Phage resistance is monitored by 11 determining the efficiency of plaquing (EOP) after challenge with virulent Lambda 12 phage. B) The effects of leuO (pKEDR13) and cas3 (pWUR608) expression on phage 13 resistance is monitored in E. coli K12 $\triangle$ CRISPRI::CRISPRJ3 (indicated as J3) C) The 14 effect of introducing the casABCDE12 (pWUR607), cas3 or a CRISPR on phage 15 resistance is monitored in E. coli $\mathrm{K} 12 \triangle$ CRISPRI::CRISPRJ3 (indicated as J3). 


\section{$1 \quad$ Table 1}

2 Microarray analysis of activation of cas genes by LeuO.

\begin{tabular}{|c|c|c|c|c|}
\hline \multirow[b]{2}{*}{ gene } & \multicolumn{4}{|c|}{ Microarray analysis of activation of cas genes by LeuO } \\
\hline & fold-change $^{a}$ & $p$ value $^{\mathrm{b}}$ & fold-change $^{\mathrm{a}}$ & $p$ value $^{\mathrm{b}}$ \\
\hline cas3 & 1.0 & n. s. 0.93 & 1.1 & n. s. 0.76 \\
\hline $\operatorname{cas} A$ & 65.4 & $<0.05$ & -1.2 & n. s. 0.08 \\
\hline $\operatorname{cas} B$ & 30.0 & $<0.05$ & -1.1 & n. s. 0.20 \\
\hline $\operatorname{cas} C$ & 24.8 & $<0.05$ & 1.0 & n. s. 0.81 \\
\hline casD & 17.5 & $<0.05$ & 1.1 & n. s. 0.68 \\
\hline casE & 15.4 & $<0.05$ & -1.2 & n. s. 0.31 \\
\hline casl & 8.8 & $<0.05$ & 1.2 & $<0.05$ \\
\hline cas 2 & 5.4 & $<0.05$ & 1.1 & n. s. 0.34 \\
\hline
\end{tabular}

$3{ }^{\mathrm{a}}$ The fold change of cas genes expression was determined by microarray analysis. $\mathrm{pLeuO} / \mathrm{wt}$

4 indicates the ratio of cas transcripts detected upon overexpression of LeuO (using plasmid

5 pKEDR13) as compared to wildtype E.coli K12 (transformed with the empty vector plasmid

6 pKESK22). $\triangle l e u O / \mathrm{wt}$ indicates the ratio of cas transcripts detected in a $\triangle l e u O_{F R T}$ mutant as

7 compared to wildtype.

$8 \quad$ b.s. is not significant 
A

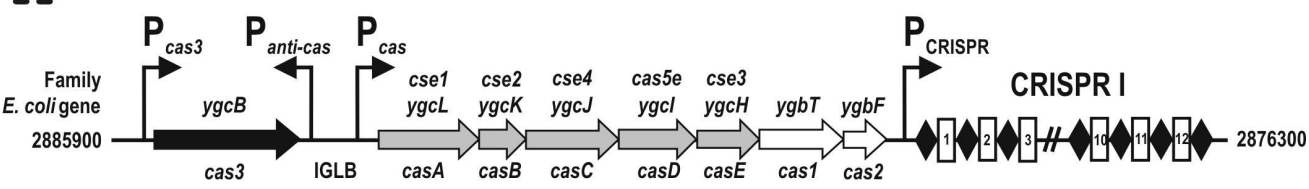

B

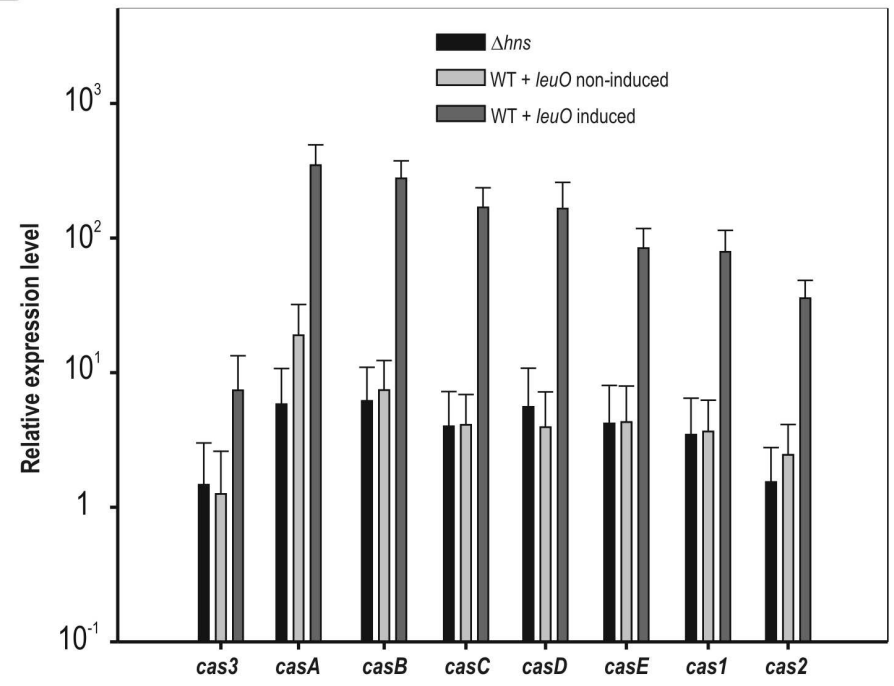




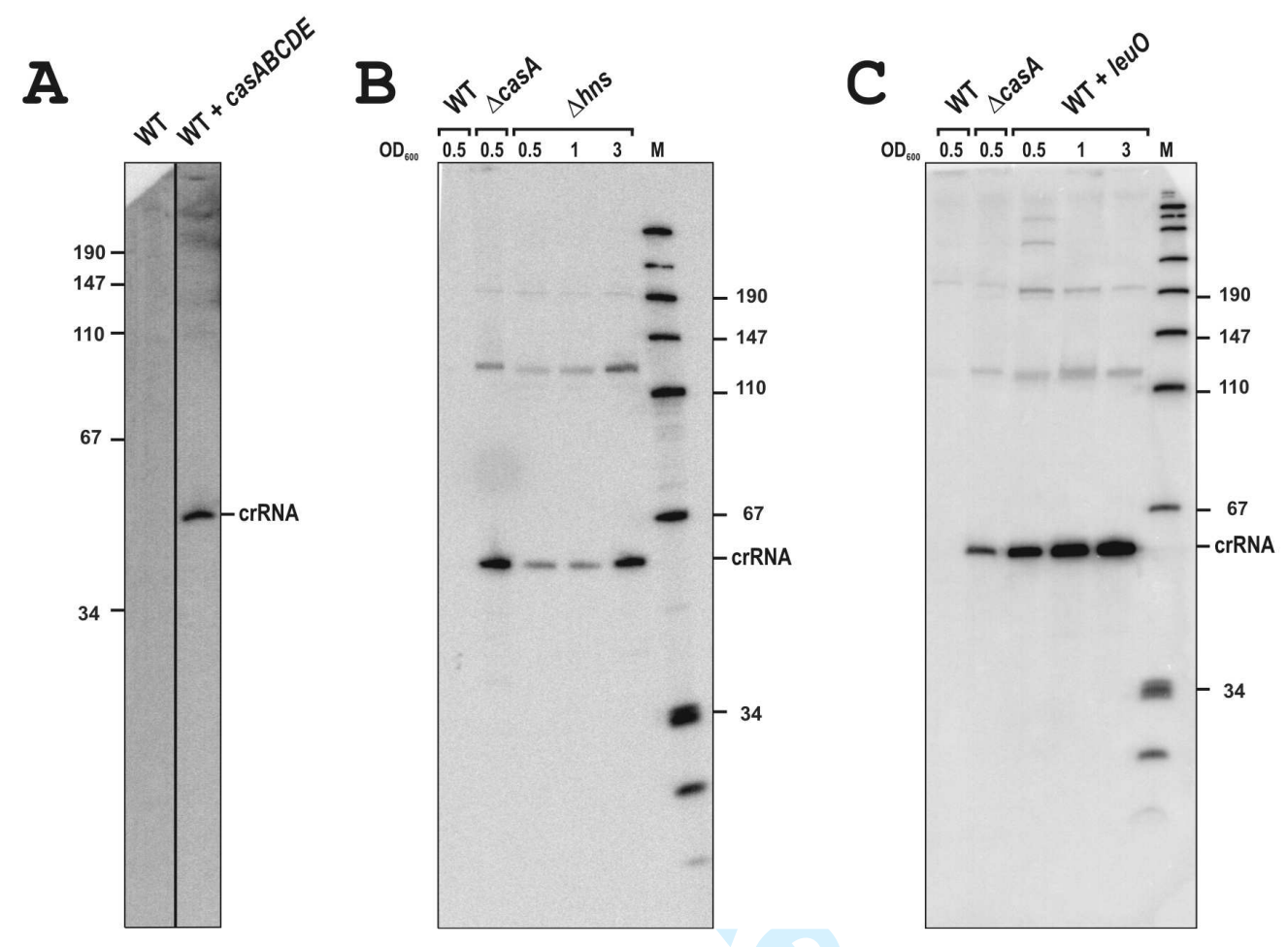


A

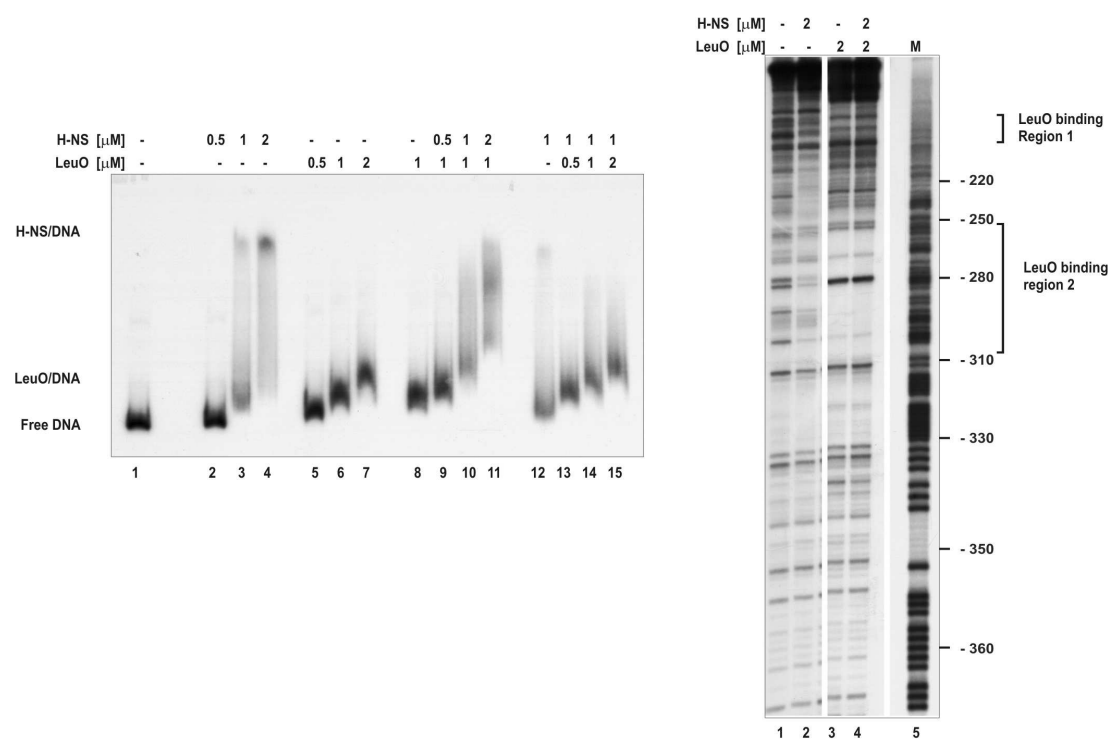

C

$\begin{array}{llllllll}-410 & -400 & -390 & -380 & -370 & -360 & -350 & -340\end{array}$ CTTCGGGAAT GATTGTTATC AATGACGATA ATAAGACCAA TAACGGTTPA TCCCTACTTA AGTAGGGAG GTGCACAATG

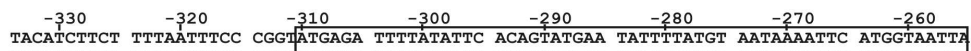
ATGTAGAAGA AAATTAAAGG GCCATACTCT AAAATATAAG TGTCATACTT ATAAAATACA TTATTTTAAG TACCATTAAT LeuO binding region II

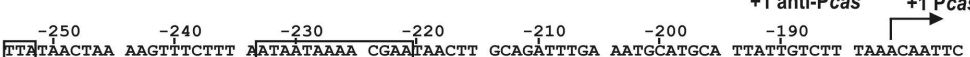

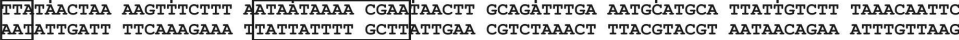
H-NS nucleation site

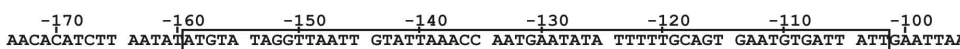

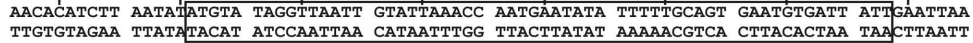
LeuO binding region I

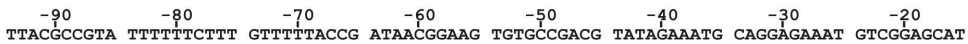
AATGCGGCAT AAAAAAGAAA CAAAAATGGC TATTGCCTTC ACACGGCTGC ATATCTTTAC GTCCTCTTTA CAGCCTCGTA

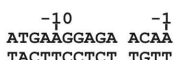


A
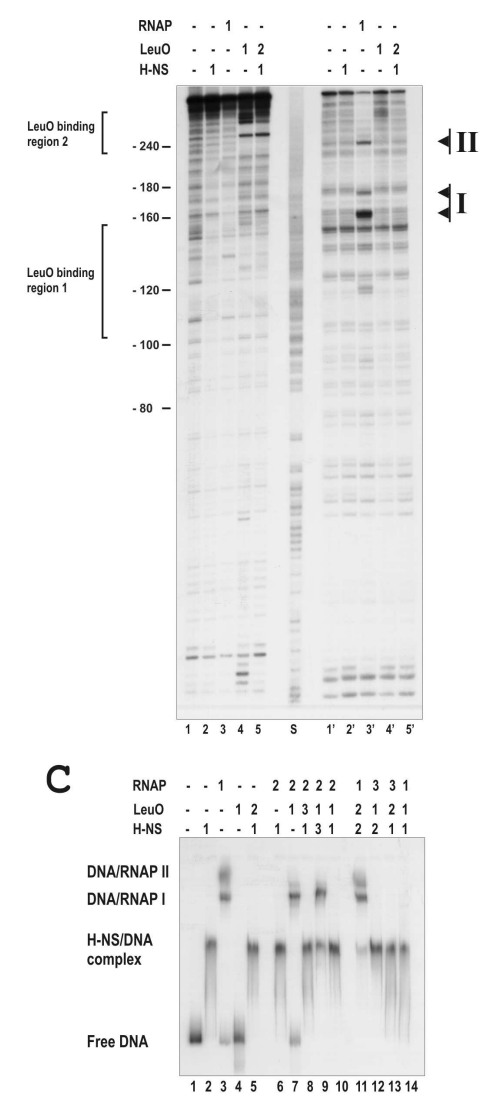

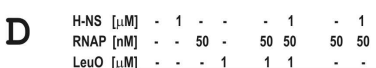

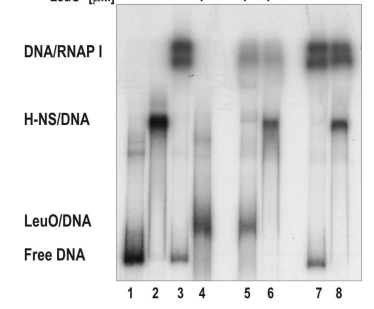

B
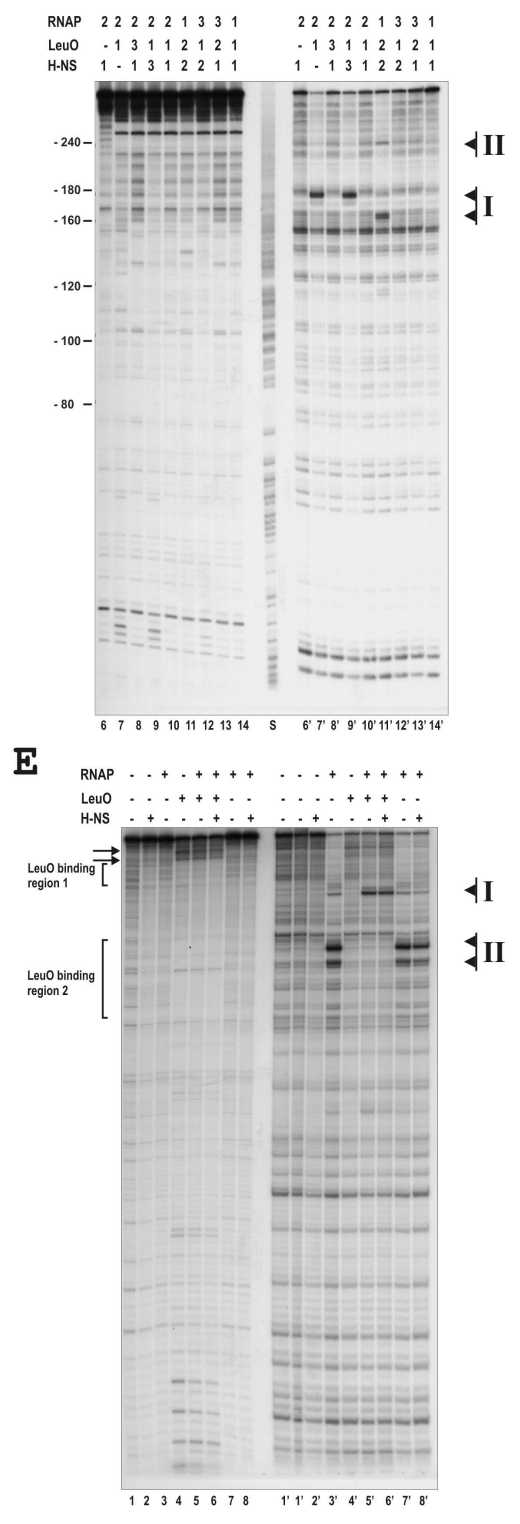

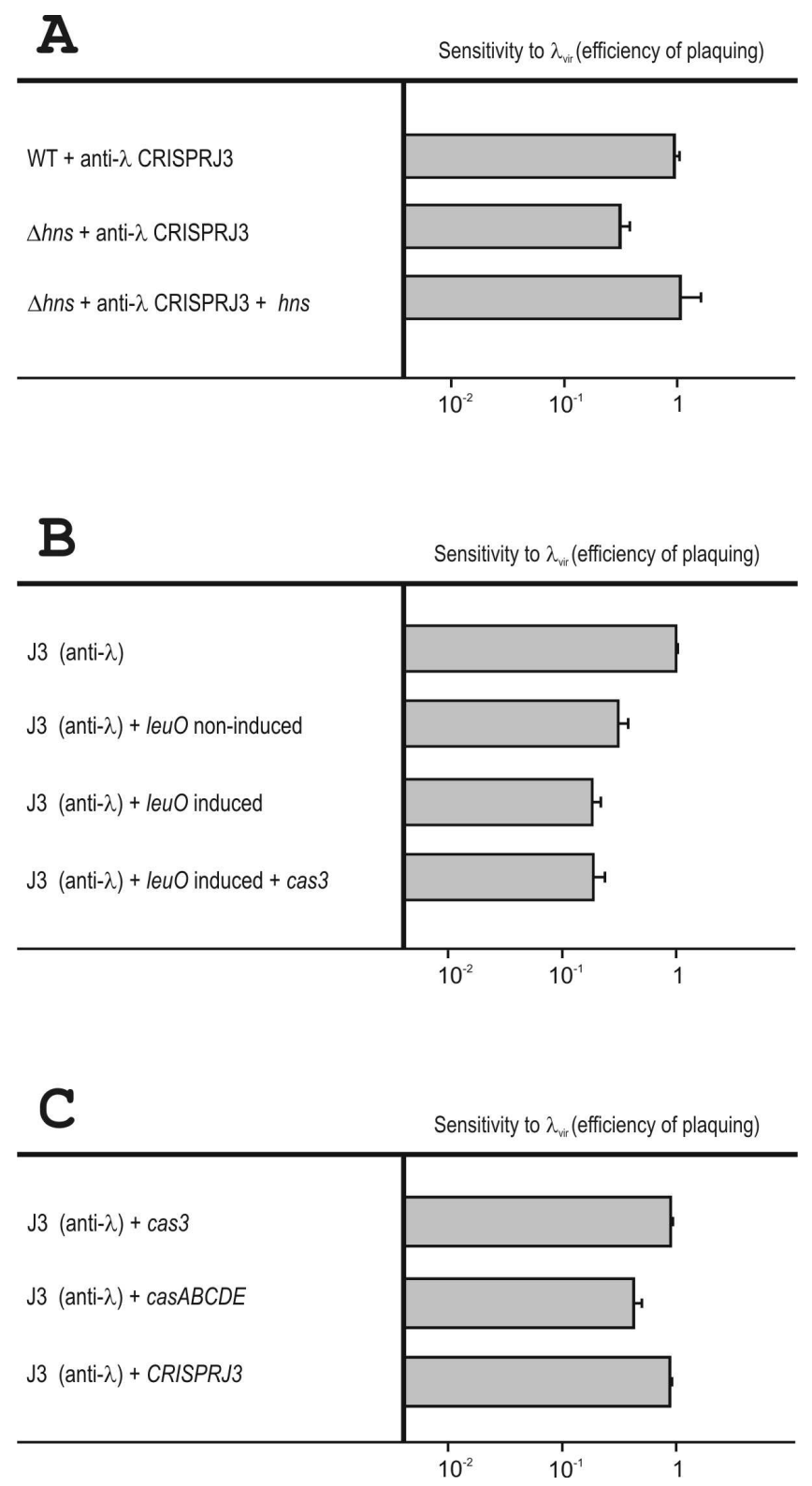